
\title{
25 Research Square \\ Retinal Optical Coherence Tomography Angiography Findings of Acute Anterior Uveitis
}

\section{Gülay Yalçınkaya ( $\nabla$ ykgulay@gmail.com )}

Beyoglu Eye Training and Research Hospital: Prof Dr N Resat Belger Beyoglu Goz Egitim ve Arastirma Hastanesi https://orcid.org/0000-0001-6248-5902

\section{Çiğdem Altan}

Beyoglu Eye Training and Research Hospital: Prof Dr N Resat Belger Beyoglu Goz Egitim ve Arastirma Hastanesi

\section{Berna Başarır}

Beyoglu Eye Training and Research Hospital: Prof Dr N Resat Belger Beyoglu Goz Egitim ve Arastirma Hastanesi

İhsan Çakır

Beyoglu Eye Training and Research Hospital: Prof Dr N Resat Belger Beyoglu Goz Egitim ve Arastirma Hastanesi

\section{Research Article}

Keywords: Anterior uveitis, foveal avascular zone, microvasculature, OCTA, optical coherence tomography angiography, vessel density

Posted Date: June 15th, 2021

DOI: https://doi.org/10.21203/rs.3.rs-576509/v1

License: (c) (i) This work is licensed under a Creative Commons Attribution 4.0 International License.

Read Full License

Version of Record: A version of this preprint was published at International Ophthalmology on November 27th, 2021. See the published version at https://doi.org/10.1007/s10792-021-02129-w. 


\section{Abstract}

Purpose: To evaluate the changes in retinal microvasculature in eyes with anterior uveitis (AU) using optical coherence tomography angiography.

Methods: Foveal avascular zone (FAZ) of superficial capillary plexus (SCP) and deep capillary plexus (DCP), vessel density (VD) of SCP, DCP, and choriocapillaris, and central macular thickness (CMT) and central foveal thickness (CFT) were calculated from 34 healthy and 41 uveitic eyes. The parameters were compared between the two groups.

Results: The deep FAZ was significantly lower in the eyes with AU during the attack than after recovery and the control group ( $p=0.001$ and $p=0.003$, respectively). The VD in deep capillary plexus (DCP) in eyes with $A U$ during the attack was significantly higher than the control group $(p=0.048)$. The VD in the foveal sector of DCP in eyes with AU during the attack and after recovery was significantly higher than the control group ( $p=0.001$ and $p=0.031$, respectively). There was no significant difference regarding CMT, CFT, VDs of each segment and each sector, and superficial and deep FAZ between eyes with first uveitis attack and those with recurrent uveitis during the attack and after recovery $(p>0.05)$.

Conclusion: The results of this study show that there is a reduction in the FAZ and an increase in the VD of the DCP of the retina during active $A U$, and these findings are reversible. Acute AU may affect the macular microvasculature, which is usually temporary, especially in the DCP.

\section{Introduction}

The most prevalent inflammatory disease of eye is the uveitis which is a leading cause of vision loss, especially in young populations [1]. The most common form of uveitis is anterior uveitis (AU), which accounts for $49 \%$ of all cases [1]. It is described by inflammation in primarily the iris and/or ciliary body. Posterior segment changes are a frequent manifestation of uveitis regardless matter where the disease is located [2-6].

In around $15 \%$ of $A U$ cases with vitritis, macular edema, papillitis, the posterior segment may be secondarily affected $[7,8]$. Even mild forms of AU could cause changes in the posterior segment that may not be observed via biomicroscopic fundus examinations [9]. Retinal vascular complications are one of the more frequent manifestations in the posterior segments $[10,11]$.

Fluorescein angiography (FA) is commonly used as a diagnostic tool to detect vascular changes in uveitis [12]. However, it is invasive and may cause allergic reactions [13]. Furthermore, it has a reasonably restricted depth resolution, so deeper capillaries are difficult to visualize [13].

Optical coherence tomography angiography (OCTA) is a recent tool that provides detailed data on the retinal and choroidal vasculature using contrast of movement [14]. The advantages of OCTA are that it is 
noninvasive, it can be done within seconds, it captures scans that can be segmented to certain depths without the use of a dye, provides data about the exact size and location [15].

The aim of this study is to evaluate the changes in retinal and choroidal vasculature in eyes with AU using OCTA.

\section{Methods}

This study was conducted in the uvea department of the University of Health Sciences Turkey, Beyoglu Eye Training and Research Hospital, Istanbul, Turkey. It was performed per the Declaration of Helsinki and approved by the University of Health Sciences Turkey Ethics Committee with decision number 12/5 on July 24,2020 . Informed consent was obtained from all patients.

We enrolled consecutive patients who presented with acute AU. Patients were excluded if they had panuveitis, intermediate uveitis, or posterior uveitis; eyes with less than $2+$ inflammatory cells in the anterior chamber according to SUN grading [16] at the first presentation; previous macular disease; glaucoma; ocular or systemic disease; medication causing macular edema; or a history of intraocular surgery.

We took detailed systemic and ophthalmologic histories of the patients. We then performed an ocular examination in both eyes, including determination of the best-corrected visual acuity (BCVA) with a Snellen chart, slit-lamp examination, and dilated fundus examination with a $90 \mathrm{D}$ lens. Spherical and cylindrical refractions of eyes were within $\pm 3.00 \mathrm{D}$ and within $\pm 2.00 \mathrm{D}$, respectively. Laboratory and radiological investigations and consultations were requested to detect systemic disease if needed.

All patients were given cycloplegics and mydriatics ( $1 \%$ tropicamide suspension and $25 \mathrm{mg} / \mathrm{ml}$ phenylephrine hydrochloride) and an intensive topical steroid (1\% prednisolone acetate suspension every hour while awake). We gradually tapered the steroid during follow-up. We administered a systemic steroid (intramuscular methylprednisolone at $1 \mathrm{mg} / \mathrm{kg}$ ) or subconjunctival steroid (4 mg of dexamethasone phosphate in $1 \mathrm{ml}$ ) when necessary, depending on the severity of inflammation and response to treatment.

An experienced technician performed OCTA using a swept-source OCT device with angiography (Topcon DRI OCT Triton swept-source OCT, Topcon, Japan) on all patients at the first visit for acute AU and when inflammation in the anterior chamber completely disappeared after treatment. All scans were captured over a $6 \times 6 \mathrm{~mm}$ fovea centered field. Three images were acquired for each eye, and the analysis was done using the scan with the greatest quality (without motion artifacts and with a signal strength index $\geq 70$ ).

Three en-face OCTA images were obtained from each scan with automated segmentation (performed by IMAGEnet-6-V.1.14.8538) at the superficial capillary plexus (SCP), deep capillary plexus (DCP), and choriocapillaris levels. The foveal avascular zone (FAZ) area of the SCP and DCP was measured from enface images that were obtained from the SCP and DCP. According to automated segmentation, the SCP 
extends from $2.6 \mu \mathrm{m}$ under the internal limiting membrane to $15.6 \mu \mathrm{m}$ under the inner plexiform layer $(\mathrm{IPL})$, the DCP is between the inner and outer boundaries at 15.6 and $70.2 \mu \mathrm{m}$ under the IPL, respectively.

The vessel density (VD) of SCP, DCP, and choriocapillaris in the fovea and parafoveal region were obtained. VD was supplied in the 5 sectors (foveal, superior, temporal, inferior, and nasal) for each segment. The FAZ sizes were measured from the SCP and DCP en-face images by the same investigator who was blind to the status of the eyes. The central macular thickness (CMT) and central foveal thickness (CFT) were recorded as well.

The patients' healthy eyes were considered as the control group if they met the inclusion criteria except for inflammation. Recovery was defined as the presence of $1+$ or less inflammatory cells in the anterior chamber according to SUN grading [16]. Previously described parameters were compared between eyes with acute $\mathrm{AU}$ and healthy eyes. The measurements taken during the acute $\mathrm{AU}$ attack were compared with those taken from the same eye after recovery. The parameters of eyes with the first uveitis attack were also compared to those with recurrent uveitis.

Statistical analyses were performed with the Statistical Package for the Social Sciences (SPSS, v.20, Chicago, IL, USA). BCVA was transformed to the logarithm of the minimum angle of resolution. All data were normally distributed according to the Kolmogorov-Smirnov test. An independent-sample and paired samples t-tests were used for comparisons. The relationship between vascular parameters (VD of SCP, DCP, choriocapillaris, and superficial and deep FAZ) and CMT and CFT was evaluated using Pearson's correlation. The results were stated as the mean \pm standard deviation, and $p<0.05$ was considered significant.

\section{Results}

The study enrolled 75 eyes of 41 patients ( 14 female, 27 male). The eyes excluded from the study comprised 2 vitrectomized eyes because of epiretinal membrane (ERM), 3 eyes with ERM, 1 eye with macular hole, and 1 eye that had a history of blunt trauma. In total, 34 healthy eyes (control group) and 41 eyes with AU were analyzed. The demographics of the patients are listed in table 1.

Therapy with a topical suspension of $1 \%$ prednisolone acetate was given to all patients for their uveitic eyes during the attack and was tapered gradually. The subconjunctival steroid was administered to three eyes that had fibrin reactions. Intramuscular methylprednisolone was administered for three consecutive days to one patient with fibrin that did not regress with other forms of steroid administration. None of the patients were on immunomodulatory therapy other than steroids at the beginning of the study and during follow-up.

Table 2 shows the mean BCVA, superficial and deep FAZ values, CMT and CFT of the healthy and study groups during active uveitis and after recovery. There was a significant difference in BCVA between the control group and the eyes with an AU attack ( $\mathrm{p} \otimes 0.001$ ). The improvement of the mean BCVA after recovery in eyes with acute $A U$ was also significant (p\0.001). Figure 1 demonstrates the FAZ areas in the 
SCP and DCP en-face images of the same eye with AU during the attack and after recovery. Deep FAZ area was significantly lower in eyes with $\mathrm{AU}$ attack compared to recovery period of them and also to the control group ( $p=0.001$ and $p=0.003$, respectively). The BCVA and the superficial and deep FAZ values in the control group were similar between the AU attack and recovery visits $(p>0.05)$. The BCVA and the superficial and deep FAZ values were also similar after recovery between the control group and the uveitis group $(p>0.05)$.

There was a significant decrease in CMT in the recovery period in the uveitis group compared to the attack period $(p=0.005)$. The CMT was significantly higher in the uveitis group than the control group during the attack $(p=0.02)$. But the CFT was similar between groups and between attack and recovery times $(p>0.05)$.

Tables 2 and 3 show the mean VD for each segment and in each sector of DCP in the control group and the eyes with AU during the attack and after recovery. Figure 2 shows an example of a quantitative assessment of VDs in each segment in the same eye with $A U$ during the attack and after recovery. There was a significant decrease in the mean VD in DCP in the eyes with AU after recovery $(p=0.04)$. The mean $V D$ in $D C P$ in eyes with $A U$ during the attack was significantly higher than the control group $(p=0.048)$, but the mean VD in DCP after recovery was similar between the groups $(p>0.05)$.

The mean VD in the foveal sector of DCP was significantly higher in eyes with AU during the attack and after recovery than in the control group $(p=0.001$ and $p=0.03$, respectively). The mean VDs for each segment and the mean VDs in each sector of DCP between the AU attack and after recovery were similar in the control group $(p>0.05)$.

There was no significant difference regarding CMT, CFT, VDs of each segment and each sector, and superficial and deep FAZ between eyes with first uveitis attack and those with recurrent uveitis during the attack and after recovery $(p>0.05)$.

The CMT was negatively correlated with superficial and deep FAZ during the attack $(R=-0.326, p=0.004$, and $R=-0.420, p<0.001$, respectively) and after the recovery $(R=-0.280, p=0.02$, and $R=-0.267, p=0.02$, respectively). During the attack, CMT was positively correlated with VD of $\operatorname{SCP}(R=0.342, p<0.001)$ and $\mathrm{DCP}(\mathrm{R}=0.342, \mathrm{p}=0.003)$. After recovery, there was a positive correlation between CMT and VD of SCP $(R=0.248, p=0.02)$.

The CFT was also negatively correlated with superficial and deep FAZ during the attack $(R=-0.347, p=$ 0.002 , and $R=-0.449, p<0.001$, respectively) and after the recovery $(R=-0.421, p<0.001$, and $R=-0.419, p$ $<0.001$, respectively). During the attack, CFT was positively correlated with VD of DCP $(R=0.245, p=$ $0.03)$. After recovery, CFT was positively correlated with VD of SCP $(R=0.248, p=0.03)$ and $D C P(R=$ $0.283, p=0.01)$.

\section{Discussion}


This detailed research investigated retinal microvasculature evaluated by OCTA in eyes affected by AU. We noninvasively evaluated FAZ and VD in patients with AU during the attack using OCTA and compared the results to normal eyes. This is the first study to investigate the retinal vascularity alterations determined by OCTA on acute AU only. Our results show that there was a transient increase in VD of DCP during the AU attack, especially in the foveal sector of DCP, and the area of deep FAZ transiently decreased during the attack.

Regardless of the anatomic location in uveitis, the underlying intraocular inflammation can lead to microvascular changes in the macula $[6,17-19]$. This is postulated to be a result of the discharge of inflammatory mediators that break the inner and outer blood-retinal barrier $[5,19,20]$. This breakdown which can cause microvascular alterations, occurs even in AU, probably due to the spread of inflammatory mediators from the anterior to the posterior segment [5, 9]. FA can be used to detect microvascular alterations. Chi et al. detected cystoid macular edema with peripheral vascular leakage in eyes with AU using FA [21]. During FA, early-phase frames are requisite in identifying microvascular changes and in the scanning of the capillaries before dye leakage [12]. It is hard to capture improved images, primarily because of the limited duration of the early scans, light scattering, and early dye leakage [22]. Furthermore, FA has a poor resolution of the DCP, it is invasive and it entails a risk of anaphylaxis [23].

OCTA is a non-contact imaging tool that provides a depth-resolved view of both the retinal and the choroidal microvasculature. It compares sequential scans and detects motion contrast via analyzing blood cells movement over time [24]. It is repeatable and ensures almost histological resolution for analysis of VD [25]. It allows for both qualitative and quantitative assessment of the vessels and facilitates the measurement of FAZ $[26,27]$. OCTA ensures high-resolution scans of both the SCP and DCP and visualization of microvascular alterations, that are not detected via FA [28]. OCTA provides important clues about the DCP that may be selectively affected in inflammation [29]. Assessment of the changes in DCP may give additional information concerning the effects of inflammation in uveitis [29]. However, it may not detect blood flow $<0.3 \mathrm{~mm} / \mathrm{s}$ and $>2 \mathrm{~mm} / \mathrm{s}$ [29]. It cannot show leakage, which may be advantageous in some cases as it provides microvascular morphological detail in all segments [29]. It provides a static image and is more prone to artifacts [15,27]. Even though blood cells are the sole moving element in the retina, some non-vascular factors can also cause a signal [15].

Khairallah et al. compared FA and OCTA in Behcet's uveitis and found that FAZ sizes in both the SCP and DCP were larger in uveitic eyes [12]. They declared that OCTA allowed better visualization of perifoveal vascular changes than FA in Behcet's uveitis [12]. It was reported that deep foveal and parafoveal VDs in OCTA images were significantly lower in Behcet's uveitis [27]. Tian et al. detected more frequent changes in choriocapillaris and DCP than in the SCP in intermediate uveitis via OCTA [30].

Kim et al. measured the retinal microvasculature in anterior and posterior uveitis using OCTA, by randomly dividing patients into 3 groups [26]. They applied different processing and segmentation settings to each group and found that there were significantly lower VD in SCP and DCP of uveitic eyes 
than those of healthy eyes [26]. They showed that there were no differences in any parameter based on anatomic classification of uveitis [26]. Nevertheless, there were 7 and 8 eyes with AU was in groups 1 and 2 , respectively, and there were not any eyes with AU in group 3 [26]. In addition, they did not exclude patients with diabetes [26]. Detection of lower VD in DCP may be the result of mechanical displacement by the macular edema or due to weakening of the DCP signal by the macular edema.

In our study, the exclusion of eyes with macular edema prevented a decrease in signal quality and mechanical displacement effects. The mean VD in DCP was significantly higher in eyes with AU during the attack than after recovery in our study $(p=0.04)$. In the control group, the mean VD in DCP was significantly lower than in the eyes with $A U$ during the attack, especially in the foveal sector of DCP $(p=$ 0.048 for DCP, $p=0.001$ for the foveal sector of DCP). After recovery, VD in each segment including DCP were similar between the uveitis and the control group $(p>0.05)$. We hypothesize that inflammatory mediators may disturb the blood-retinal barrier and thus increase blood flow, VD, and permeability. Nevertheless, we presume that these changes caused by inflammatory mediators may be temporary. Although the mean VD in DCP in the control and uveitis groups did not change significantly after recovery, surprisingly, there was a significant increase in VD in the foveal sector of DCP $(p=0.03)$. Prospective studies are necessary to explain this result.

It was postulated that eyes with AU had larger superficial and deep FAZ compared to healthy controls in the presence of macular edema and they could not be differentiated from healthy controls in the absence of macular edema [31]. However, there were only 6 eyes without macular edema and 5 eyes with macular edema in the AU group in the same study [31]. We found that deep FAZ was diminished significantly $(p=$ 0.001 ) in the eyes with AU during the attack. None of our cases had macular edema. Deep FAZ area was significantly lower in eyes with AU attack compared to the control group $(p=0.003)$ whereas superficial FAZ changes during the AU attack were not significant. Deep FAZ was similar between the control and the uveitis group after recovery $(p>0.05)$, so we can hypothesize that the decrease in deep FAZ was not permanent.

Basarir et al. evaluated HLA-B27 positive AU and found that the CMTs of both affected and unaffected eyes had no differences [32]. Unlike this, the CMT was significantly reduced in uveitic eyes after recovery in our study $(p=0.005)$. The relationship between VD, FAZ and retinal thickness has been reported [3335]. Yu et al. found that retinal thickness was positively correlated with VD and negatively correlated with the FAZ area [34]. It was noted that at the level of SCP and DCP, VD was correlated with the macular thickness $[33,35]$ and there was a negative correlation between foveal thickness and superficial FAZ area in normal eyes [35]. Our results are consistent with those in the literature. We found a negative correlation of superficial and deep FAZ with CMT and CFT, and there was a correlation between VD of SCP and DCP and retinal thickness.

Despite the inclusion of a higher number of eyes than in previous studies, our study has limitations: All patients were from the same center, which limits the generalizability of the results. We evaluated all AU cases as a whole and did not group patients based on etiology. Instead of making repeated 
measurements at regular intervals during the recovery period, measurements were taken in the period after complete recovery. Therefore, the correlation between the degree of anterior chamber inflammation (aqueous flare and/or cell) and OCTA parameters could not be evaluated.

In conclusion, we showed significant changes in the affected eye during AU attacks when compared to unaffected eyes, which mostly resolved when inactivity was achieved. We detected a reduction in the FAZ and an increase in the VD of the DCP of the retina during active AU, and these findings were reversible. According to our results, AU may affect the macular microvasculature, which is usually temporary, especially in the DCP. OCTA provides a detailed image of the macular microvasculature, making it possible to detect these microvascular changes. Further prospective trials with larger sample sizes could provide an idea about the effects of the disease in the posterior segment and perhaps treatment monitoring and prognosis.

\section{Declarations}

Competing interests: The authors declare that they have no conflict of interest.

Funding: No financial support was received.

Conflicts of interest: The authors declare that they have no conflict of interest.

Ethics approval: All procedures performed in studies involving human participants were in accordance with the ethical standards of the institutional and national research committee and with the 1964 Helsinki Declaration and its later amendments or comparable ethical standards. Ethical approval was obtained through the University of Health Sciences Turkey Ethics Committee (12/5 on July 24, 2020).

Consent to participate: Written informed consent was obtained from all individual participants included in the study.

Consent for publication: Patients signed informed consent regarding publishing their data.

Availability of data and material: The data that support the findings of this study are available from the corresponding author, upon reasonable request.

Code availability: Not applicable.

Authors' contributions: All authors contributed to the study conception and design. Material preparation, data collection and analysis were performed by Gulay Yalcinkaya, and Ihsan Cakir. The first draft of the manuscript was written by Gulay Yalcinkaya, and all authors commented on previous versions of the manuscript. All authors read and approved the final manuscript.

Acknowledgments: Thanks to Assoc. Prof. Ahmet Kirgiz for his comments and suggestions. 


\section{References}

1. Rothova A, Suttorp-van Schulten M, Treffers WF, Kijlstra A (1996) Causes and frequency of blindness in patients with intraocular inflammatory disease. British Journal of Ophthalmology 80: 332-336

2. Pivetti-Pezzi P, Accorinti M, La Cava M, Gisoldi RAC, Abdulaziz MA (1996) Endogenous uveitis: an analysis of 1,417 cases. Ophthalmologica 210: 234-238

3. Liu T, Bi H, Wang X, Gao Y, Wang G, Ma W (2015) Macular abnormalities in Chinese patients with uveitis. Optometry and Vision Science 92: 858-862

4. Durrani O, Tehrani N, Marr J, Moradi P, Stavrou P, Murray P (2004) Degree, duration, and causes of visual loss in uveitis. British Journal of Ophthalmology 88: 1159-1162

5. Freeman G (2001) Cystoid macular oedema in uveitis: an unsolved problem. Eye 15: 12-17

6. Antcliff RJ, Stanford MR, Chauhan DS, Graham EM, Spalton DJ, Shilling JS, Marshall J (2000) Comparison between optical coherence tomography and fundus fluorescein angiography for the detection of cystoid macular edema in patients with uveitis. Ophthalmology 107: 593-599

7. Feldtkeller E, Khan M, van der Heijde D, van der Linden S, Braun J (2003) Age at disease onset and diagnosis delay in HLA-B27 negative vs. positive patients with ankylosing spondylitis. Rheumatology international 23: 61-66

8. Monnet D, Breban M, Hudry C, Dougados M, Brézin AP (2004) Ophthalmic findings and frequency of extraocular manifestations in patients with HLA-B27 uveitis: a study of 175 cases. Ophthalmology 111: 802-809

9. Gabriel M, Kruger R, Shams-Mafi F, Hermann B, Zabihian B, Schmetterer L, Drexler W, Binder S, Esmaeelpour M (2017) Mapping retinal and choroidal thickness in unilateral nongranulomatous acute anterior uveitis using three-dimensional 1060-nm optical coherence tomography. Investigative ophthalmology \& visual science 58: 4778-4783

10. Garcia-Diaz M, Mira M, Nevado L, Galvan A, Berenguer A, Bureo JC (1995) Retinal vasculitis associated with Crohn's disease. Postgraduate medical journal 71: 170-172

11. Keyser BJ, Hass AN (1994) Retinal vascular disease in ulcerative colitis. American journal of ophthalmology 118: 395-396

12. Khairallah M, Abroug N, Khochtali S, Mahmoud A, Jelliti B, Coscas G, Lupidi M, Kahloun R, Yahia SB (2017) Optical coherence tomography angiography in patients with Behçet uveitis. Retina 37: 16781691

13. Spaide RF, Klancnik JM, Cooney MJ (2015) Retinal vascular layers imaged by fluorescein angiography and optical coherence tomography angiography. JAMA ophthalmology 133: 45-50

14. Chalam K, Sambhav K (2016) Optical coherence tomography angiography in retinal diseases. Journal of ophthalmic \& vision research 11: 84

15. De Carlo TE, Romano A, Waheed NK, Duker JS (2015) A review of optical coherence tomography angiography (OCTA). International journal of retina and vitreous 1: 5 
16. Group SoUNW (2005) Standardization of uveitis nomenclature for reporting clinical data. Results of the First International Workshop. American journal of ophthalmology 140: 509-516

17. Karampelas M, Sim DA, Chu C, Carreno E, Keane PA, Zarranz-Ventura J, Westcott M, Lee RW, Pavesio CE (2015) Quantitative analysis of peripheral vasculitis, ischemia, and vascular leakage in uveitis using ultra-widefield fluorescein angiography. American journal of ophthalmology 159: 1161-1168. e1161

18. Graham E, Stanford M, Shilling J, Sanders M (1987) Neovascularisation associated with posterior uveitis. British journal of ophthalmology 71: 826-833

19. Howes EL, Cruse VK (1978) The structural basis of altered vascular permeability following intraocular inflammation. Archives of Ophthalmology 96: 1668-1676

20. Rotsos TG, Moschos MM (2008) Cystoid macular edema. Clinical ophthalmology (Auckland, NZ) 2: 919

21. Chi Y, Guo C, Peng Y, Qiao L, Yang L (2015) A prospective, observational study on the application of ultra-wide-field angiography in the evaluation and management of patients with anterior uveitis. Plos one 10: e0122749

22. Coscas F, Glacet-Bernard A, Miere A, Caillaux V, Uzzan J, Lupidi M, Coscas G, Souied EH (2016) Optical coherence tomography angiography in retinal vein occlusion: evaluation of superficial and deep capillary plexa. American journal of ophthalmology 161: 160-171. e162

23. Kornblau IS, El-Annan JF (2019) Adverse reactions to fluorescein angiography: a comprehensive review of the literature. Survey of ophthalmology 64: 679-693

24. Cerquaglia A, Lupidi M, Fiore T, laccheri B, Perri P, Cagini C (2017) Deep inside multifocal choroiditis: an optical coherence tomography angiography approach. International ophthalmology 37: 10471051

25. Matsunaga D, Yi J, Puliafito CA, Kashani AH (2014) OCT angiography in healthy human subjects. Ophthalmic Surgery, Lasers and Imaging Retina 45: 510-515

26. Kim AY, Rodger DC, Shahidzadeh A, Chu Z, Koulisis N, Burkemper B, Jiang X, Pepple KL, Wang RK, Puliafito CA (2016) Quantifying retinal microvascular changes in uveitis using spectral-domain optical coherence tomography angiography. American journal of ophthalmology 171: 101-112

27. Aksoy FE, Basarir B, Altan C, Pasaoglu I, İnal A, Tunç U, Ocak OB, Karabulut GO (2020) Retinal microvasculature in the remission period of Behcet's uveitis. Photodiagnosis and photodynamic therapy 29: 101646

28. Pichi F, Sarraf D, Arepalli S, Lowder CY, Cunningham Jr ET, Neri P, Albini TA, Gupta V, Baynes K, Srivastava SK (2017) The application of optical coherence tomography angiography in uveitis and inflammatory eye diseases. Progress in retinal and eye research 59: 178-201

29. Pichi F, Sarraf D, Morara M, Mazumdar S, Neri P, Gupta V (2017) Pearls and pitfalls of optical coherence tomography angiography in the multimodal evaluation of uveitis. Journal of ophthalmic inflammation and infection 7: 1-12 
30. Tian M, Tappeiner C, Zinkernagel MS, Huf W, Wolf S, Munk MR (2019) Evaluation of vascular changes in intermediate uveitis and retinal vasculitis using swept-source wide-field optical coherence tomography angiography. British Journal of Ophthalmology 103: 1289-1295

31. Waizel M, Todorova MG, Terrada C, LeHoang P, Massamba N, Bodaghi B (2018) Superficial and deep retinal foveal avascular zone OCTA findings of non-infectious anterior and posterior uveitis. Graefe's Archive for Clinical and Experimental Ophthalmology 256: 1977-1984

32. Basarir B, Celik U, Altan C, Celik NB (2018) Choroidal thickness changes determined by EDI-OCT on acute anterior uveitis in patients with HLA-B27-positive ankylosing spondylitis. International ophthalmology 38: 307-312

33. Park SH, Cho H, Hwang SJ, Jeon B, Seong M, Yeom H, Kang MH, Lim HW, Shin YU (2020) Changes in the retinal microvasculature measured using optical coherence tomography angiography according to age. Journal of clinical medicine 9: 883

34. Yu J, Gu R, Zong Y, Xu H, Wang X, Sun X, Jiang C, Xie B, Jia Y, Huang D (2016) Relationship between retinal perfusion and retinal thickness in healthy subjects: an optical coherence tomography angiography study. Investigative ophthalmology \& visual science 57: ОСT204-ОCT210

35. Zhang Z, Huang X, Meng X, Chen T, Gu Y, Wu Y, Wu Z (2017) In vivo assessment of macula in eyes of healthy children 8 to 16 years old using optical coherence tomography angiography. Scientific reports 7: 1-9

\section{Tables}


Table 1

The demographics of the patients.

\begin{tabular}{|c|c|c|}
\hline & $\begin{array}{l}\text { Eyes with anterior uveitis } \\
(n=41)\end{array}$ & $\begin{array}{l}\text { Control group } \\
(n=34)\end{array}$ \\
\hline $\begin{array}{l}\text { Age (years) } \\
\text { mean } \\
\text { range }\end{array}$ & $\begin{array}{l}41.9 \pm 13.9 \\
17-81\end{array}$ & $\begin{array}{l}42.6 \pm 14.7 \\
17-81\end{array}$ \\
\hline $\begin{array}{l}\text { Sex }(n) \\
\text { female } \\
\text { male }\end{array}$ & $\begin{array}{l}14 \\
27\end{array}$ & $\begin{array}{l}11 \\
23\end{array}$ \\
\hline $\begin{array}{l}\text { Property of lens }(\mathrm{n}) \\
\text { clear } \\
\text { nuclear cataract } \\
\text { posterior subcapsular cataract }\end{array}$ & $\begin{array}{l}32 \\
7 \\
2\end{array}$ & $\begin{array}{l}30 \\
3 \\
1\end{array}$ \\
\hline $\begin{array}{l}\text { Etiology }(n) \\
\text { Viral } \\
\text { HLA B27 associated } \\
\text { Idiopathic }\end{array}$ & $\begin{array}{l}9 \\
14 \\
18\end{array}$ & - \\
\hline $\begin{array}{l}\text { History of anterior uveitis (n) } \\
\text { first attack } \\
\text { recurrent uveitis }\end{array}$ & $\begin{array}{l}25 \\
16\end{array}$ & - \\
\hline $\begin{array}{l}\text { Number of attacks per year } \\
\text { mean } \\
\text { range }\end{array}$ & $\begin{array}{l}1.54 \pm 1.19 \\
1-6\end{array}$ & - \\
\hline $\begin{array}{l}\text { Anterior chamber cells during the attack } \\
\text { mean } \\
\text { range }\end{array}$ & $\begin{array}{l}3.34 \pm 0.94 \\
2-5\end{array}$ & - \\
\hline $\begin{array}{l}\text { Anterior chamber cells after recovery } \\
\text { mean } \\
\text { range }\end{array}$ & $\begin{array}{l}0.27 \pm 0.45 \\
0-1\end{array}$ & - \\
\hline
\end{tabular}


Table 2

The mean BCVA, superficial and deep FAZ values, vessel densities for each segment, CMT and CFT of the control and study groups during active uveitis and after recovery.

\begin{tabular}{|c|c|c|c|c|c|c|c|c|}
\hline & $\begin{array}{l}\text { Uveitis } \\
\text { group } \\
\text { during the } \\
\text { attack }\end{array}$ & $\begin{array}{l}\text { Uveitis } \\
\text { group } \\
\text { after } \\
\text { recovery }\end{array}$ & $\begin{array}{l}p^{1} \\
\text { value }\end{array}$ & $\begin{array}{l}\text { Control } \\
\text { group } \\
\text { during the } \\
\text { attack }\end{array}$ & $\begin{array}{l}\text { Control } \\
\text { group } \\
\text { after } \\
\text { recovery }\end{array}$ & $\begin{array}{l}p^{2} \\
\text { value }\end{array}$ & $\begin{array}{l}p^{3} \\
\text { value }\end{array}$ & $\begin{array}{l}\mathrm{p}^{4} \\
\text { value }\end{array}$ \\
\hline $\begin{array}{l}\text { BCVA } \\
\text { (logMAR) }\end{array}$ & $\begin{array}{l}0.37 \pm \\
0.37\end{array}$ & $\begin{array}{l}0.19 \pm \\
0.30\end{array}$ & $\otimes 0.001$ & $\begin{array}{l}0.10 \pm \\
0.24\end{array}$ & $\begin{array}{l}0.10 \pm \\
0.24\end{array}$ & * & \.001 & 0.15 \\
\hline $\begin{array}{l}\text { Superficial } \\
\text { FAZ, } \mu \mathrm{m}^{2}\end{array}$ & $\begin{array}{l}191.22 \pm \\
95.06\end{array}$ & $\begin{array}{l}200.31 \pm \\
102.34\end{array}$ & 0.26 & $\begin{array}{l}232.27 \pm \\
92.50\end{array}$ & $\begin{array}{l}233.85 \pm \\
98.86\end{array}$ & 0.79 & 0.06 & 0.16 \\
\hline $\begin{array}{l}\text { Deep FAZ, } \\
\mu \mathrm{m}^{2}\end{array}$ & $\begin{array}{l}174.56 \pm \\
87.34\end{array}$ & $\begin{array}{l}203.58 \pm \\
97.48\end{array}$ & 0.001 & $\begin{array}{l}239.58 \pm \\
94.03\end{array}$ & $\begin{array}{l}241.84 \pm \\
86.42\end{array}$ & 0.84 & 0.003 & 0.08 \\
\hline SCP (\%) & $\begin{array}{l}41.99 \pm \\
1.76\end{array}$ & $\begin{array}{l}41.57 \pm \\
1.84\end{array}$ & 0.17 & $\begin{array}{l}41.83 \pm \\
1.71\end{array}$ & $\begin{array}{l}42.09 \pm \\
1.77\end{array}$ & 0.39 & 0.72 & 0.21 \\
\hline DCP (\%) & $\begin{array}{l}43.55 \pm \\
2.12\end{array}$ & $\begin{array}{l}42.82 \pm \\
1.86\end{array}$ & 0.04 & $\begin{array}{l}42.59 \pm \\
2.02\end{array}$ & $\begin{array}{l}42.66 \pm \\
2.21\end{array}$ & 0.81 & 0.048 & 0.74 \\
\hline CC (\%) & $\begin{array}{l}52.93 \pm \\
1.51\end{array}$ & $\begin{array}{l}52.87 \pm \\
1.45\end{array}$ & 0.73 & $\begin{array}{l}52.90 \pm \\
1.43\end{array}$ & $\begin{array}{l}52.95 \pm \\
1.52\end{array}$ & 0.73 & 0.92 & 0.82 \\
\hline $\mathrm{CMT}, \mu \mathrm{m}$ & $\begin{array}{l}268.98 \pm \\
23.73\end{array}$ & $\begin{array}{l}262.37 \pm \\
25.74\end{array}$ & 0.005 & $\begin{array}{l}257.29 \pm \\
19.12\end{array}$ & $\begin{array}{l}256.62 \pm \\
18.56\end{array}$ & 0.56 & 0.02 & 0.28 \\
\hline $\mathrm{CFT}, \mu \mathrm{m}$ & $\begin{array}{l}192.22 \pm \\
25.08\end{array}$ & $\begin{array}{l}190.51 \pm \\
22.39\end{array}$ & 0.38 & $\begin{array}{l}186.44 \pm \\
13.60\end{array}$ & $\begin{array}{l}186.88 \pm \\
12.81\end{array}$ & 0.73 & 0.23 & 0.41 \\
\hline \multicolumn{9}{|c|}{$\begin{array}{l}\text { BCVA best-corrected visual acuity, FAZ foveal avascular zone, CMT central macular thickness, CFT } \\
\text { central foveal thickness, logMAR the logarithm of the minimum angle of resolution, SCP superficial } \\
\text { capillary plexus, DCP deep capillary plexus, CC choriocapillaris, } \mathrm{p}^{1} \text { value between attack and recovery } \\
\text { in the uveitis group, } \mathrm{p}^{2} \text { value between attack and recovery in the control group, } \mathrm{p}^{3} \text { value between the } \\
\text { control group and the uveitis group during the attack, } \mathrm{p}^{4} \text { value between the control group and the } \\
\text { uveitis group after recovery, }{ }^{*} \text { The correlation cannot be computed because the standard error of the } \\
\text { difference is zero. }\end{array}$} \\
\hline
\end{tabular}


Table 3

The mean vessel densities in each sector of deep capillary plexus of the control and study groups during active uveitis and after recovery.

\begin{tabular}{|c|c|c|c|c|c|c|c|c|}
\hline & $\begin{array}{l}\text { Uveitis } \\
\text { group } \\
\text { during the } \\
\text { attack }\end{array}$ & $\begin{array}{l}\text { Uveitis } \\
\text { group } \\
\text { after } \\
\text { recovery }\end{array}$ & $\begin{array}{l}p^{1} \\
\text { value }\end{array}$ & $\begin{array}{l}\text { Control } \\
\text { group } \\
\text { during the } \\
\text { attack }\end{array}$ & $\begin{array}{l}\text { Control } \\
\text { group } \\
\text { after } \\
\text { recovery }\end{array}$ & $\begin{array}{l}p^{2} \\
\text { value }\end{array}$ & $\begin{array}{l}p^{3} \\
\text { value }\end{array}$ & $\begin{array}{l}\mathrm{p}^{4} \\
\text { value }\end{array}$ \\
\hline $\begin{array}{l}\text { Foveal } \\
(\%)\end{array}$ & $\begin{array}{l}21.34 \pm \\
5.26\end{array}$ & $\begin{array}{l}20.19 \pm \\
5.69\end{array}$ & 0.07 & $\begin{array}{l}17.37 \pm \\
4.84\end{array}$ & $\begin{array}{l}17.51 \pm \\
4.65\end{array}$ & 0.68 & 0.001 & 0.03 \\
\hline $\begin{array}{l}\text { Superior } \\
(\%)\end{array}$ & $\begin{array}{l}50.66 \pm \\
3.31\end{array}$ & $\begin{array}{l}50.01 \pm \\
3.15\end{array}$ & 0.26 & $\begin{array}{l}50.61 \pm \\
3.10\end{array}$ & $\begin{array}{l}50.29 \pm \\
2.88\end{array}$ & 0.51 & 0.95 & 0.69 \\
\hline $\begin{array}{l}\text { Temporal } \\
(\%)\end{array}$ & $\begin{array}{l}46.47 \pm \\
3.41\end{array}$ & $\begin{array}{l}46.56 \pm \\
2.81\end{array}$ & 0.88 & $\begin{array}{l}46.99 \pm \\
2.53\end{array}$ & $\begin{array}{l}46.82 \pm \\
2.27\end{array}$ & 0.69 & 0.46 & 0.66 \\
\hline $\begin{array}{l}\text { Inferior } \\
(\%)\end{array}$ & $\begin{array}{l}50.57 \pm \\
3.84\end{array}$ & $\begin{array}{l}49.35 \pm \\
4.93\end{array}$ & 0.11 & $\begin{array}{l}50.18 \pm \\
4.33\end{array}$ & $\begin{array}{l}50.30 \pm \\
4.92\end{array}$ & 0.89 & 0.68 & 0.41 \\
\hline $\begin{array}{l}\text { Nasal } \\
(\%)\end{array}$ & $\begin{array}{l}48.74 \pm \\
3.90\end{array}$ & $\begin{array}{l}47.97 \pm \\
2.96\end{array}$ & 0.29 & $\begin{array}{l}47.79 \pm \\
2.97\end{array}$ & $\begin{array}{l}48.39 \pm \\
4.14\end{array}$ & 0.22 & 0.25 & 0.61 \\
\hline
\end{tabular}

\section{Figures}




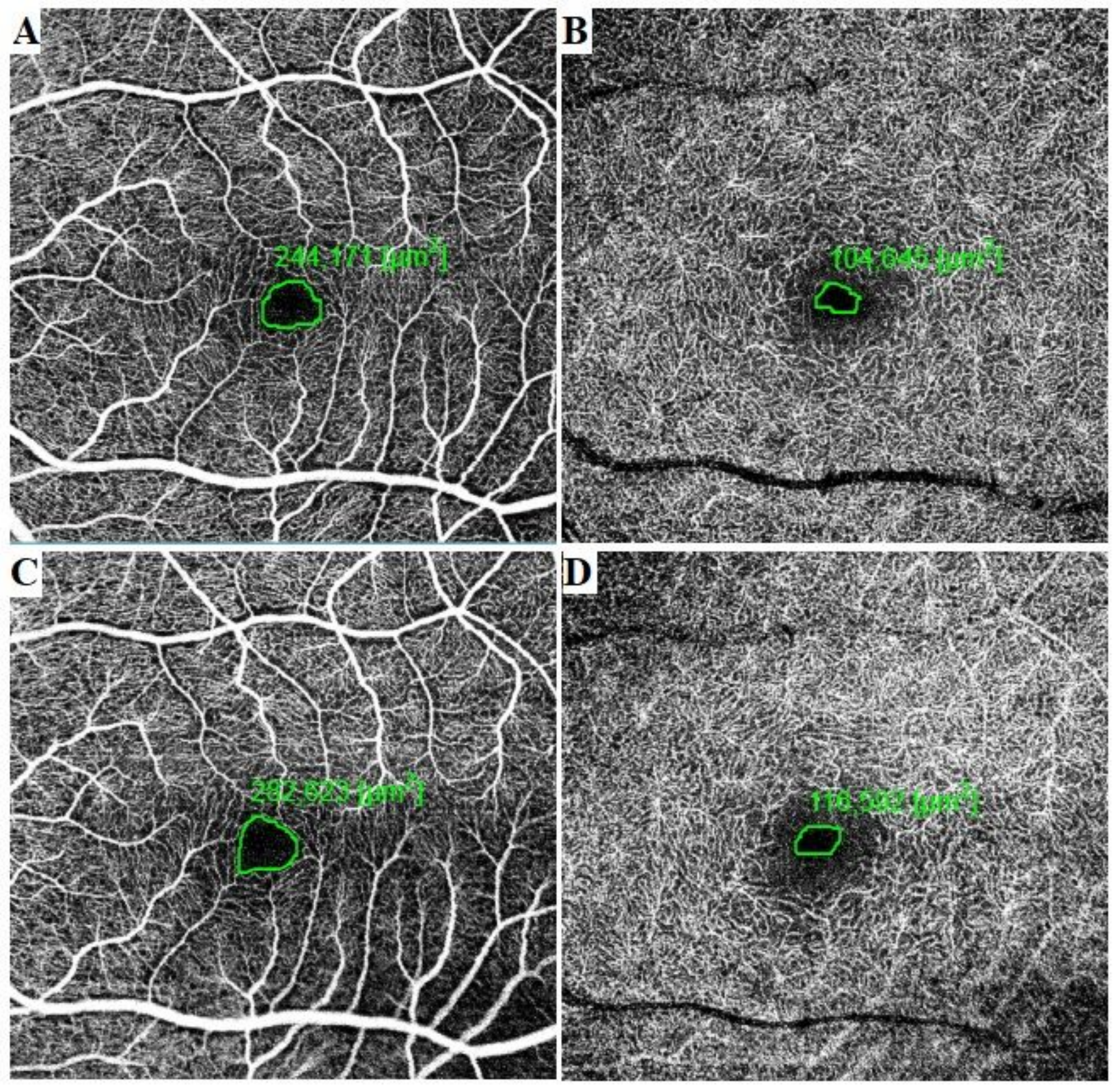

Figure 1

Foveal avascular zone (FAZ) areas in the same eye with anterior uveitis. Superficial (A) and deep (B) FAZ during active uveitis. Superficial (C) and deep (D) FAZ after recovery. 


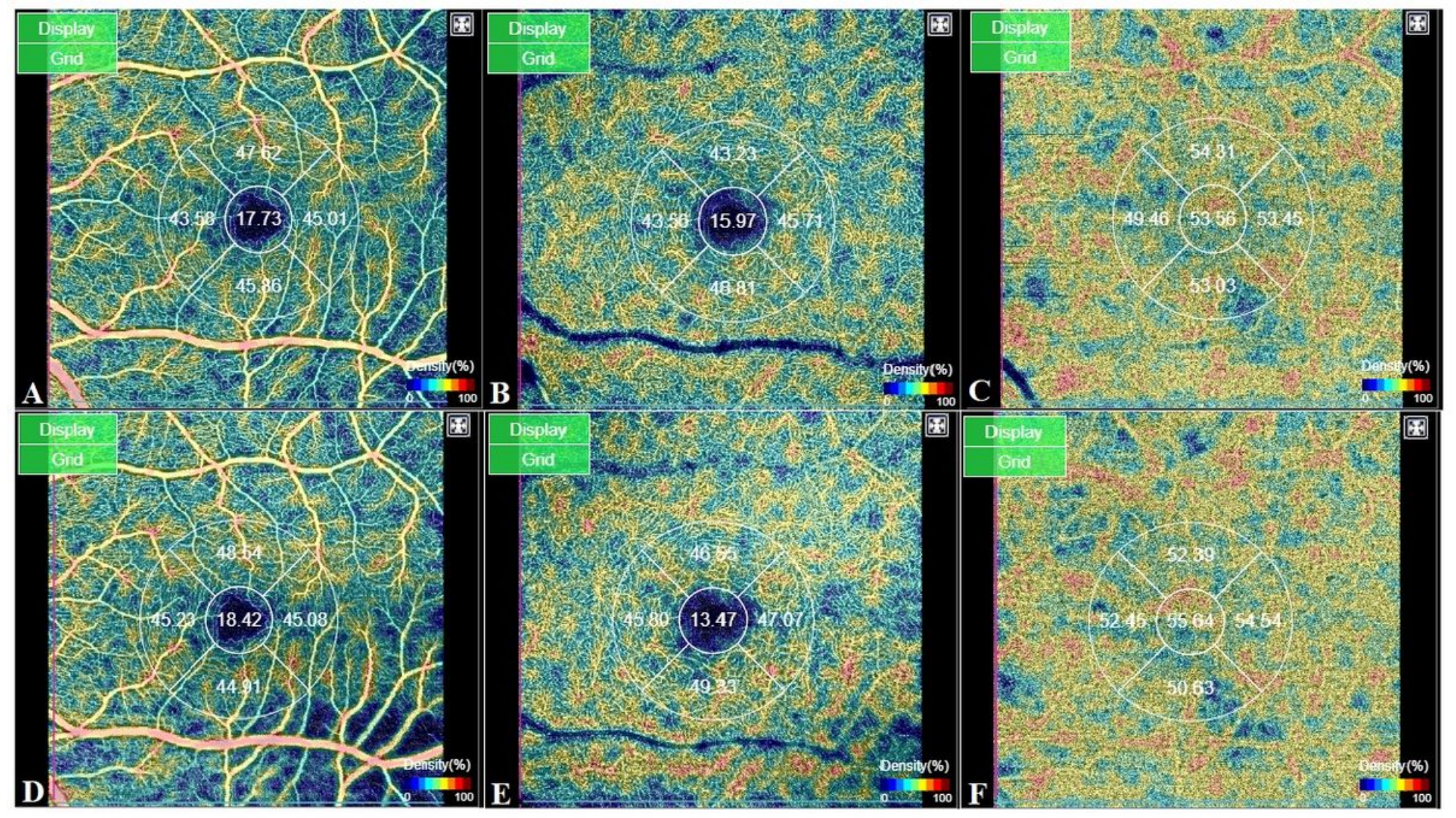

\section{Figure 2}

An example of a quantitative assessment of vessel densities in each segment in the same eye with active uveitis (on top) and after recovery (on bottom). Superficial (A and D), deep (B and E) capillary plexuses and choriocapillaris (C and F). 